the veins of another. No parasite or germ of any descrip. tion has ever been identified in connexion with this fever, and if such should ever be shown to exist it will probably be ultra microscopic. The incubation period has been shown to be from two to four days; this was found to be more or less constant in many of my cases in which this point could be made out.

\section{Racial Incidence.}

This is peculiar. In Chitral it is remarkable that Europeans and Gurkha sepoys suffer to the extent of 60 per cent. to 80 per cent., while other details of the garrison who have lived previously for the most part in thie plains of the Punjab have been practically free from the fever. The Chitrali people themselves do not appear to suffer from the disease except in early infancy. Doubt. less they acquire a high degree of immunity in early childhood which protects them throughout later life. The existence of the disease in the Punjab will also explain the fact that while a hospital may be crowded out with Gurkha sepoys, who go down like flies before the epidemic, hardly a single Punjabi will be attacked. The Gurkhas have always previously lived in hill stations where the fever has not existed, while the Punjabi has come up to Chitral for his year's duty from the plains of the Punjab where he has acquired a high degree of immunity from previous attacks. The percentage of Europeans attacked is eren greater than among the Gurkhas of the garrison. As a rule one attack confers immunity against fresh attacks, though this is by no means constant. I have seen fresh attacks to the extent of 5 per cent. of all cases, and have myself contracted the fever in each of two successive years. Even cases of third attack have been noted in the same epidemic, though these are rare.

Some epidemics are much more severe than others, and the circumstances which influence the type of the severity of an epidemic are difficult to make out. In the first of my three epidemics (in 1911) something over 200 cases occurred, being about 40 per cent. of all who had been cxposed; while in 1912 exactly 400 cases occurred, that is, about 70 per cent. of total exposed, though the conditions in the two years were almost identical and the type of the actual cases of the two epidemics showed no marked difference.

\section{Symptoms.}

After an incubation period of from two to four days, during which there are usually no prodromal symptoms beyond slight headache and general malaise in some cases, the disease usually begins with a rigor. The temperature rises rapidly in a few hours, reaching a maximum varying from $103^{\circ}$ to $105^{\circ}$ or $106^{\circ} \mathrm{F}$. by the end of the first twenty. four hours. The fever usually lasts two to three days, generally with a slight remission on the second dav. The action of the virus manifests itself by general symptoms: Acute aching pains and stiffness all over the body, especially in the muscles of the back and limbs, severe frontal headache, and pain in the back of the eyes. Injection of the conjunctival vessels is also present, producing the "pink eye" described by some observers in Crete. Nasal and pharyngeal catarrh are occasional symptoms, but this catarrh never extends to the bronchi or lungs. Disturbances of the digestive system are invariably noticed; anorexia is a pronounced symptom, vomiting is not common, constipation is the rule. The spleen is generally unchanged.

Among the circulatory signs most noticeable is brady. cardia. Many cases, even with a temperature of $104^{\circ}$ or $105^{\circ} \mathrm{F}$., will show a pulse-rate of less than 80 , or even less than 70 , and rarely over 100 , and during convalescence this bradycardia is still more pronounced.

Blood changes are very slight. Leucopenia, with a relative large mononuclear increase, was found in some cases. No protozoal or other micro-organisms were ever found in any cases, though the blood of all cases was care. fully examined microscopically with a high power. Epistaxis was a very common symptom, being noticed in over 20 per cent. of my cases. In some cases this epistaxis was a troublesome symptom and hard to control, possibly indicating a diminished degree of coagulability of the blood. No cases showed any sign of a rash, which has occasionally been noticed by other observers.

\section{Treatment.}

Treatment on the ordinary lines for pyrexia was adopted as a routine. Quinine has absolutely no effect on the fever. Aspirin $I$ found of use; if given in fairly large doses the aching pains in the muscles and the severe frontal headache were considerably relieved. Given shortly before the usual hour for sleep, the use of this drug made all the difference in the night's comfort in many cases. Tincture of opium and salicylates were also used in many cases with gratifying results, at least from the former.

\section{Diagnosis.}

The diagnosis seldom presented any difficulty during the epidemic season. The sudden onset, with rapidly rising temperature and slow pulse, are characteristic.

\section{Prognosis.}

The prognosis is never serious. No cases terminato fatally, and complications or troublesome sequelac ara exceptional, except the very marked degree of prostration, which lasts from ten days to a fortnight at least, and is very constantly present in almost all cases. It would appear that the virus has a marked depressing effect on the central nervous system, producing this severe prostration. Occasionally the temperature chart will show a sharp rise of temperature about three or four days after. its return to normal. Such relapses, however, are not common; my figures only show 1 per cent. of such cases.

\section{Prophylaxis.}

Evacuation of localities where the disease is known to be present should be carried out where practicable. It is not always possible, however, to do this, especially in a frontier station where a fort has to be kept occupied.

Experience in Chitral has proved that if the troops of tho garrison can spend the three or four special fever montlis of the hot weather under canvas at an elevation of any. thing over 7,000 ft. not a single case of sandfly fever will occur amongst such troops, while any troops remaining in the fort, which is situated at an elevation of just under $5,000 \mathrm{ft}$., will contract the fever to the extent of nearly 80 per cent. during the epidemic season.

Very early isolation of cases should be strictly carried out, inasmuch as inoculation experiments have shown that it is only during the early stage of the disease that the case can be considered infectious. All cases should be liept under a (fine mesh) sandfly-proof curtain erected over each bed. A similar curtain should, of course, be used by all persons living in an infected area. 'The demolition of all unnecessary buildings and old wallsideal haunts for the sandfly - is desirable. Various drugs have been recommended for external use as repellents, but they havo not proved of much value. Fumigation of rooms of barracks has been tried, with temporary good results in some cases by killing off numbers of sandflies. Déstruction of sandflies by spraying the walls of buildings with some insecticide, such as formalin solution, has been recommended, but I have not given this method a trial in Chitral, as I do not consider that it could be conveniently carried out. Indeed, it must be admitted that very littlo reliance can be placed on any methods hitherto employed with a view to reducing the fever incidence by diminishing the number of sandflies.

In conclusion I should like to emphasize the fact that although sandfly fever is a very distressing type of fever, I do not think that of the 700 cases or more which came under my notice during the year's 1911 to 1913 any one patient is now any the worse for his attack. The fever is not a serious one when compared with other tropical fovers, such as malaria. Recovery from sandfly fever may be considered to be absolute in all cases, and a consider able degree of immunity from fresh attacks usually results. But as a severe cause for temporarily rendering a large percentage of a unit inefficient it requires to be dealt with carefully.

\section{SANDFLY FEVER IN PESHAWAR.}

\section{Captain J. W. houston, M.B., R.A.M.C.}

As long ago as 1899 Colonel Fooks saw an epidemic of short fever cases at Landi Kotal, in which he considered the sandfly to be the infecting agent, and later he described 
an epiclemic which he saw amongst the 15th Lancers at Sialkote in 1907, and was again of opinion that it was conveyed by sandflies. He considered this epidemic to be one of dengue, of a three-day and a seven-day fever type, but writing later, in 1911, he said that the disease would be known as sandfly fever; but although medical officers were cognisant of this ferer, it was not until 1910 that the evidence was sufficiently strong to warrant its being officially recognized. In that year, under the heading of sandfly fever, we find that there were 103 admissions to hospital amongst the British troops in the division. In 1911 it is evident that the diagnosis was more readily made, as there was a sharp rise in the number of admis. sions to 782, and this was maintained in 1912 and 1913, when the admissions were 823 and 746 respectively. In the years previous to 1910 sandfly fever was doubtless recorded under various headings, the principal one being malaria, but influenza and pyrexia of uncertain origin also took a share.

With regard to susceptibility and incidence it would seem that all ages and both sexes are prone to be infected, but the disease has not been observed much here amongst women and children as they all depart to the hills at the commencement of the hot weatlrer. Fresh arrivals from stations where the disease is not prevalent appear to be particularly susceptible, whilst the stay of a battalion or other unit in an infected station such as this is marked by a gradual rise in immunity: An example of this may be given.

The 72nd Battery R.G.A. arrived from Nowgong last cold weather. A perusal of their medical history sheets showed that none of their men had suffered from sandfly fever. " They were quartered beside, and practically in the same barracks with, the 75th Battery R.F.A., who had been in Peshawar and district for over four years, and whose medical records show that 37 per cent. of their men hare bcen infected at one time or another. During a period of one month after the appearance of sandfly fever in April, 1914, 19 cases occurred in the fresh battery, an incidence of 112 per 1,000. Amongst the old battery 8 eases occurred, an incidence of 61 per 1,000 , or just about half. All these men were living side by side under practically identical conditions, so that it would seem that in the 75th Battery a certain degree of immunity has been establislied.

A perusal of the figures for the two British infantry battalions in the station gives a similar, though less marked, finding.

The incidence among the men of the 2nd King's (Liverpool) Regiment, a new arrival here, was, up to April 28th, 6 per 1,000 , and during the month following that date 41 per 1,000; April 28th was the date on which half of each battalion left Peshawar for the hills. In the lst Royal Sussex Regiment, who are old inhabitants, the rates of incidence before and after April 28th were respectively only 2 and 12 per 1,000 , so that here again it seems probable that some immunity has been attained.

The incidence in the two batteries was considerably greater than in the two infantry battalions, and, so far as can be observed, this coincides with the relative numbers of phlebotomi present in the various barracks. They are distinctly more numerous, and certainly occasion more complaints, amongst those inhabiting the gunner lines than amongst the residents in the infantry barracks. An interesting feature, too, is that the infection appears to cling more particularly to certain bungalows, and with the appearance of sandflies in April, cases of the fever begin to occur in these, which then form foci from which it spreads in all clirections.

The varieties of phlebotomi commonly seen in this district are $P$. papatasii and $P$. minutus. $P$. papatasii is, however, by far the most prevalent and widely distributed, and, so far as can be judged, outnumbers all the other's by at least 20 to 1 .

The disease makes its appearance with considerable suddenness about the middle of April annually, and as this coincides with the yearly advent of numbers of phlebotomi, also as the usual type of fever seems identical with that described in other parts of the world as sandfly or pappataci fever, it is reasonable to suppose that they are identical in every respect, and that the $P$. papatasii is the velicle of infection from person to person

As well as the sandfly, the north-west frontier is the home of several of the other blood-sucking diptera, but $i^{t}$ does not seem likely that any of them will be found to be implicated in the spread of this particular ferer.

The disease reaches its maximum incidence annually in May and June, though in 1913 this did not occur until August; the tendency for it then is to show a decicled fall until October is reached, after which month practically no cases occur. The clinical manifestations of sandfy fever may be described as follows: The onset is suddena man goes to bed feeling either absolutely well or he may notice some chilliness or shivering in the evening. There is no rigor. He wakes up in the morning "witl the fever on him," as he expresses it. Frequently it is ushered in with nausea and vomiting. Severe beadache is almost always complained of, the main seat of pain being at the back of the eyes. Joint pains and aching pains and cramps, chiefly in the lower limbs, are usually present, and the patient feels ill and depressed. The face is flushed and the eyes suffused. A rash has not been noted. The temperature runs up rapidly, reaching $102^{\circ} \mathrm{F}$. or $103^{\circ} \mathrm{F}$., or even higher during the first day. It tends to fall gradually until the second day, when it is usually about $100^{\circ} \mathrm{F}$. or $101^{\circ} \mathrm{F}$. The third day it may be still falling and quickly reach normal, or show a slight exacerbation to $100.8^{\circ} \mathrm{F}$. or $101^{\circ} \mathrm{F}$, this being followed by a rapid, sometimes almost critical, fall to normal. It is unusual to find any fever at all after the third or fourth day. The pulse is full and compressible. The rate is not markedly increased, seldom being beyond 88 , even when the fever is high.

The tongue is coated with a whitish fur, and a constant complaint of the patient is "a bad taste in the mouth." The bowels are, as a rule, constipated. No abdominal distension has been noted; the heart sounds do not change, and the lungs remain clear. There is no enlargement of the liver or spleen.

The blood picture is characterized by a leucopenia, the total leucocyte count averaging about 5,500 per c.mm. Differential counts show that the polymorphs are usually below 60 per cent., while the mononuclears show an increase up to 15 per cent. or over. An increase in eosinophiles up to 5 or 6 per cent. has also been noted in a few cases, but it cannot yet be said whether this feature is at all constant or not. There is no diminution in the number of red cells, nor does there appear to be any blood destruction as evidenced by an examination of the urine. In other respects also the urine is normal. As soon as the temperature becomes normal the patient usually states that he feels perfectly well, but in many instances he finds that it is a considerable time before he fully recovers his strength. One attack does not appear to confer absolute immunity against the disease, as a second or even a third in consecutive years have been noted in a few cases. In a very small percentage two attacks in one year have been recorded.

There is another type of fever seen in this part of the country during the summer months which some observers also attribute to the presence of sandflies and designate sandfly fever. In it the duration of the pyrexia is longer and runs a course of seven days so consistently as to be known as the seren-day fever type, as opposed to the three-day fever type described above. 'The general symptonis resemble those of the three-day variety, but are much less marked, and in a considerable proportion of the cases there are practically no subjective symptoms, the only marked objective one being the pyrexia. A rash is also sometimes seen. In other words, these cases resemble the "seven-day fever" described as occurring in the large coast towns of India, but also seen in Poona, Bangalore, Belgaum, and various other places. They are well marked off from the classical dengue by their more sporadic appearance and much less epidemic character, combined with their general mildness of symptoms. Nor does the evidence in favour of their being a variety of sandfly ferer appear to be strong, the main arguments against that assumption being again their rather sporadic appearance during the later warm months when phlebotomi are disappearing, whilst if we are to regard sandfly fever here as being identical with that occurring in Malta, Crete, and other places, there is the fact that when the disease has been produced experimentally it has never undergone any marked modification in the person artificially infected but has been of the original three.day type. As Stegomyia 
are found here it is at least as likely that they may be a factor in the causation of this seven-day type of rever, as they appaar to be now generally regarded as being the active agentis in its propagation in other parts of the country.

\section{THE BIONOMICS OF THE MALTESE PHLEBOTOMI.}

\section{By Captain P. J. MARETT, R.A.M.C.,} BEIT MEMORIAL RESEARCH FELLOW.

IT is places which are dark, damp, and usually inaccessible and with a requisite temperature and a suitable food supply, that the phlebotomus flies select for their breeding grounds.

That darkness is the natural condition is to be deduced from an examination of the larvae, which are devoid of eyes, their place being taken in the adult larvae by two patclies of pigment. A certain amount of moisture is necessary, for two reasous - the one, that, if placed in dry surroundings, the larva will shrivel up, and the other that the food of the larva being excretal matter, cannot be eaten when in a dry condition. Excess of moisture is equally harmful, as has been experienced in breeding experiments, where excessive spraying of a breeding dish resulted in the loss of all the larvae.

Quiet is essential, as the larval stage is somewhat lengthy, and if exposed to ins sment weather during this period a fatal result :s a foregore conclusion. The proper food supply of the larva has been found to be the excreta of the various insects and animals found in walls. Special attention has been paid to the excrement of woodlice, lizards and bats, and undoubtedly, in experimenta breeding, the first-that of woodlice-gives the best results. The requisite temperature for active breeding is above $70^{\circ} \mathrm{F}$; below $60^{\circ} \mathrm{F}$. larvae appear to roll themsclves up in detritus, whilst the higher the temperature is above $70^{\circ} \mathrm{F}$. and up to $86^{\circ} \mathrm{F}$. the more rapid is the life cycle.

All the above physical conditions are to be found in the interior of rubber walls, in crevices of caves, artificia embankments, and, in Malta especially, in the interior of the old bastions, many of which contain long disused chambers. In searching these places, of which only the interiors of the first three have been examined, the number of specimens of larvae and pupae found has not bcen in proportion to the quantities of flies prevalent, but this has been found to be due to the fact that the larvae bury themselves, and that of the pupae, in nature, only those adhering to stomes have been found. In experi mental breeding only about 5 per cent. of pupae so attach themselves, the remaining 95 per cent. lie free on or under the detritus.

Newstead, in his article on the Papatasii flies (Phlebotomus) of the Maltese Islands, describes three varieties: $P$.papatasii Scop, P.perniciosus Newstead, and $P$. minutus Rond; of these $P$. papatasii is the largest, $P$. minutus the smallest, whilst $P$.perniciosus, as regards the size of its body, resembles $P$. papatasii, but its legs are not nearly so long. P. papatasii breeds out in caves and in embankments, whilst $P$. perniciosus and $P$. minutus breed chiefly in the rubble walls and in bastions, the result being that the $t$ wo latter species are seen more often in dwelliugs, unless caves and embankments are in close proximity.

Flies appear about the middle of May, in small numbers; they gradually increase, and by the end of June they are numerous; during July, when the breeding grounds are somewhat Ary, their numbers decrease, and only on the onset of the damp sirocco, about the middle of August or beginning of September, do their numbers rise once more, when they appear in far greater numbers than earlier in the year, and persist till the onset of the rains and wind, about the middle of November. They can still be found in their breeding liaunts in small numbers during December.

The latest date on which a fly was seen was January 14th; this was in a breeding ground where the temperature kept up to $70^{\circ} \mathrm{F}$. till January; on the temperature falling to $60^{\circ} \mathrm{F}$. no flies were seen. There is thus an interval of about four months during which the adult fly is not to be found; that is to say, the fly does not hibcrnate, but the winter is passed in the larval stage.
The causes for the fluctuations noted in nature have bcen worked out experimentally; it is found that dryness of surroundings prolongs the length of the various stages, and on the other hand, that with suitable moisture and heat the various stages are passed through rapidly; in the former the complete cycle talies up to four to five months; in the latter, the shortest time has been found to be thirtyfour days.

A sunimary of the length of life of the different stages, for wild flies and for tame flies, is best given in tabulated form.

Summary of the Length of Life of the Different Stages, for Wild Flies and Tame Flies.

\begin{tabular}{|c|c|c|}
\hline \multirow{2}{*}{ Stage. } & \multicolumn{2}{|c|}{ Duration of Stage : } \\
\hline & Wild Flies. & Tame Flies. \\
\hline 1. Pragnancy stage ... & Unknown & 7 to 10 days. \\
\hline 2. Egg stage $\quad \ldots \quad \ldots$ & $\begin{array}{l}\text { (a) } 6 \text { to } 9 \text { days } \\
\text { (b) In dry wea. } \\
\text { ther up to } \\
20 \text { days }\end{array}$ & $\begin{array}{l}\text { (a) Arerage, } 8.4 \text { days. } \\
\text { (b) Shortest in incubator at } \\
30^{\circ} \text { C., } 5 \text { days. } \\
\text { (c) Longest in October at } \\
\text { room temp., } 10.1 \text { days. }\end{array}$ \\
\hline 3. First larval stage ... & 14 days & $\begin{array}{l}\text { (a) Shortest, } 6 \text { days. } \\
\text { (b) Longest, } 14 \text { days. }\end{array}$ \\
\hline 4. Total larval stage ... & Up to 5 months & $\begin{array}{l}\text { (a) Longest, } 140 \text { days. } \\
\text { (b) Averdge longest, } 92 \text { days. } \\
\text { (c) Average shortest, } 24 \text { days. }\end{array}$ \\
\hline 5. Pupal stage ... & 11 to 16 days & 6 to 16 days. \\
\hline 6. Length of life of fly & 8.4 days & $\begin{array}{l}\text { Females : } \\
\text { (a) Shortest, } 7 \text { days. } \\
\text { (b) Longest, } 25 \text { days. } \\
\text { (c) Average, } 12.5 \text { days. } \\
\text { Males: } \\
\text { Average, } 4 \text { days. }\end{array}$ \\
\hline
\end{tabular}

The above data are gathered from breeding experiments Of tame flies from the middle of August, 1913, to the end of March, 1914, four generations were bred out.

The eggs are white, but rapidly darken; they are marked with distinct patterns $(36 \mu$ by $12 \mu)$. The larvae on hatching are minute and with a dull white body, the head and the two tail hairs being a shiny black; at two days old the size of the larva is $0.4125 \mathrm{~mm}$. and the length of the tail hairs $0.5 \mathrm{~mm}$.; total length, $0.9125 \mathrm{~mm}$. They rapidly increase in size and take on the brownish colour of their surroundings; on moulting, which they do once, they once more become white, and shortly after the head and tail hairs assume the black colour, but now the larva has two pairs of tail hairs. The larva is motile and eats voraciously; when about to pupate (its size is then about $4 \mathrm{~mm}$. and tail hairs $1 \mathrm{~mm}$.; total length, $5 \mathrm{~mm}$.) it becomes motionless, empties its intestinal canal, and its head curves over till it touches its abdominal surface.

The colour of the pupa, which is obtectate, is on emergence a dull white, having its terminal segments covered by the remains of its larval slin. In a couple of days the eyes show their black pigment, and about two days prior to emergence the wings; body and legs take on their pigmentation, brownish to jet black. The size of the pupae varies with species and with sex; in $P$. papatasii the males are $4 \mathrm{~mm}$. long and are thin in comparison to the female flies; the females are $3 \mathrm{~mm}$. The extra length of the males is due to the claspers, which are held fully extended. Pupae are more resistant to the action of water than larvae.

When a larva is about to pupate, it comes up to the surface; if the surface of the detritus, however, is dry it will remain in the depths, so that under these conditions, when the fiy hatches, it has to work its way up to the surface. The fly emerges from its pupal case through a sagittal slit at its anterior extremity.

Flies are sexually mature within a few hours of emerg. ing, thus it is impossible to state the duration of pregnancy in the wild fly.

Tame flies usually feed before pairing, the females alone suck blood; when pregnancy is short (for example, seven days), the eggs are more likely to be fertile, and when this is the case, the eggs are all laid within twenty-four hours, and the fly is found dead by the last of her eggs-this is the usual course with wild flies.

With the tame fly, where eggs are laid and the fly dies 